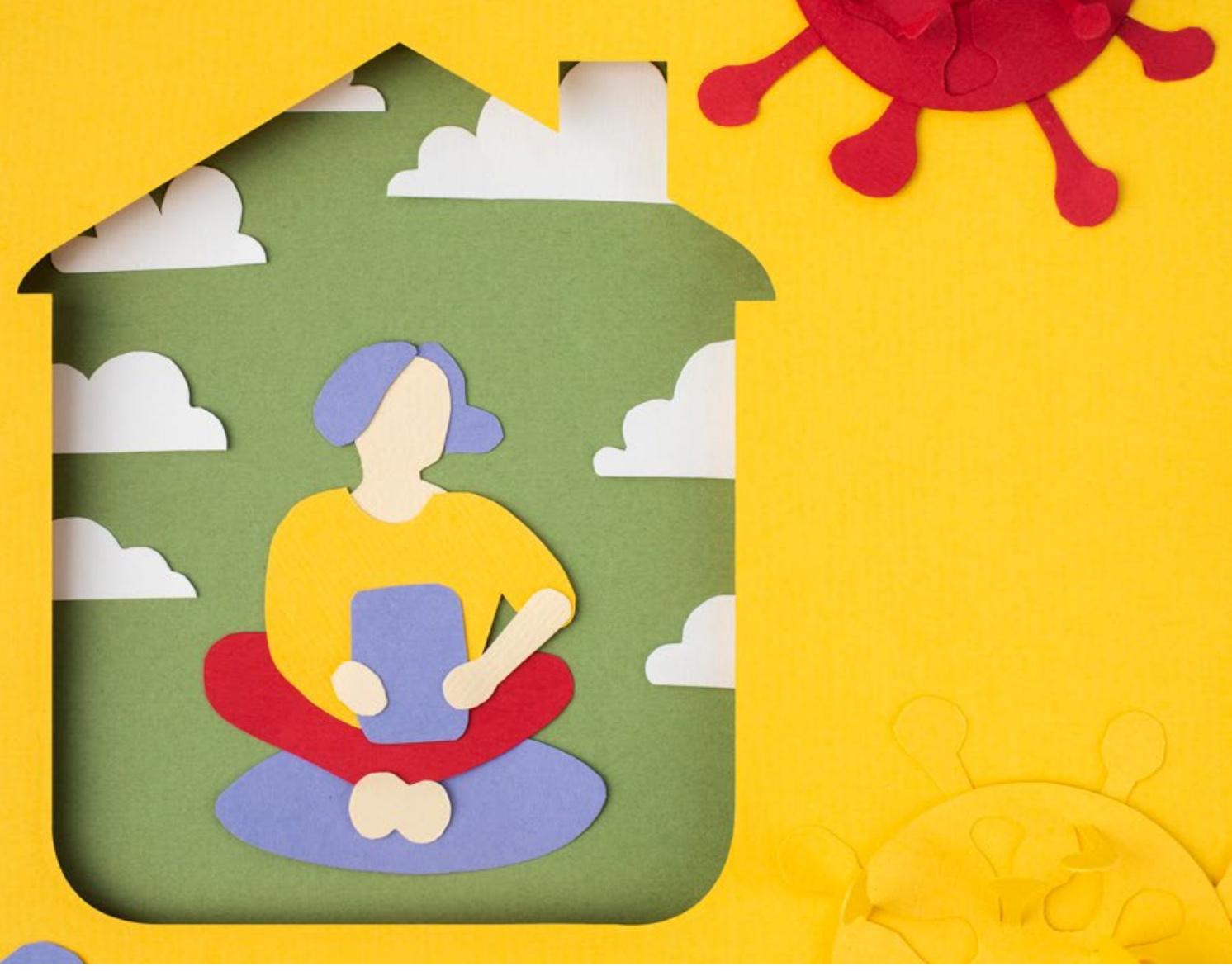

\title{
¿Funcionan las cuarentenas para prevenir los contagios?
}

Por: Lucas Berardo, Egresado Magíster en Economía, UAH; Ramiro de Elejalde, Doctor en Economía, Universidad Carlos III de Madrid, España. Académico FEN-UAH; y Eugenio Giolito, Ph.D. en Economía, University of Maryland, EE.UU. Académico FEN-UAH.

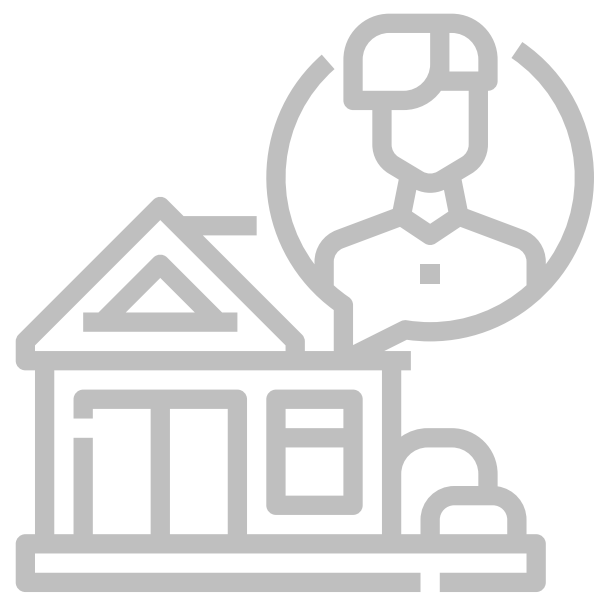

a pandemia del COVID-19 que apareció en el mundo a finales de 2019 obligó a los gobiernos a tomar medidas urgentes para disminuir la transmisión del virus y así evitar el colapso sanitario.

La principal herramienta fueron las intervenciones no farmacéuticas que, dado que el contagio se produce de persona a persona, tienen como objetivo el distanciamiento social. Entre estas medidas se encuentran la obligación de utilizar mascarillas, el cierre de escuelas y negocios no esenciales y prohibir la circulación mediante la implementación de confinamientos.

El objetivo original era, por un lado, evitar que las tasas de contagios subiesen en forma repentina llevando a un colapso del sistema sanitario y, por el otro, ganar tiempo hasta que las primeras vacunas se encuentren disponibles.
A partir del avance de la vacunación, las medidas de distanciamiento son importantes para hacer frente a episodios de incrementos de casos por la aparición de nuevas variantes mas agresivas del virus (frente a las cuales se desconoce la efectividad de las vacunas actuales).

Dado que estas políticas de distanciamientos social tienen altos costos para la sociedad, una pregunta natural es si realmente son efectivas para disminuir los contagios y bajo que condiciones son más efectivas. En particular, en el contexto de Chile, ¿han sido efectivas las políticas de confinamiento para reducir los contagios?

El primer caso de COVID-19 en Chile fue detectado el 3 de marzo de 2020. Durante las primeras semanas la propagación se concentró en el sector oriente de la Región Metropolitana (el área de mayores ingresos 
en la Región). Sin embargo, a medida que transcurrió el tiempo, el foco de contagios se fue desplazando hacia las comunas del centro y posteriormente hacia el sur que, por el contrario, se caracteriza por una población más carenciada.

Para mitigar el contagio el gobierno chileno decidió implementar cuarentenas totales o parciales a nivel de comuna. Con el recorrido de la emergencia se creó el plan Paso a Paso, donde se establecieron 5 escenarios 0 pasos graduales siendo el primero de ellos la fase de cuarentena. En esta fase se prohíbe la circulación de personas en la comuna y hacia la comuna todos los días de la semana y solo se mantienen abiertos los negocios esenciales.

Los primeros confinamientos se establecieron en el sector oriente y en Santiago centro a fines de marzo de 2020. Si bien el gobierno realizó un polémico llamado a un retorno seguro a comienzos de mayo y fue liberando algunas comunas, esto no prosperó ya que dada el alza en los contagios se decide implementar una cuarentena total en el Gran Santiago a mediados de ese mes. Esta situación se prolongó durante las siguientes semanas y no fue sino hacia fines de julio cuando se comenzaron a desconfinar las comunas del sector oriente.

Medir el efecto de las cuarentenas en la tasa de contagios presenta importantes complicaciones. Primero, no hay evidencia histórica de políticas similares para aprender de sus efectos, por lo tanto es necesario utilizar los datos recientes. Segundo, la interacción del crecimiento de los contagios, el comportamiento de las personas y la decisión del gobierno de declarar la cuarentena hace que sea difícil separar el efecto de la cuarentena de estos otros factores. Tercero, la efectividad de la cuarentena puede ser muy distintos en comunas de distinto nivel socioeconómico.

La Figura 1 muestra, por ejemplo, los períodos de cuarentena (área sombreada), la evolución de la movilidad medida como el número de viajes que se realizaron en una comuna (detectados por cambios de antenas de los dispositivos móviles) normalizado por la población (línea azul), y los casos nuevos de COVID-19 detectado en la semana (línea naranja) para las comunas de Las Condes (ingresos altos) y de La Florida (ingresos medios).

En el gráfico podemos observar que la movilidad cae con las cuarentenas, pero que se recupera a medida que la cuarentena se extiende en el tiempo. Además, este aumento de la movilidad es mucho rápido en comunas de menores ingresos. Respaldando este punto, las tasas de casos nuevos por semana cada 100.000 habitantes sigue un patrón parecido en ambas comunas, pero llega a un máximo de 800 casos nuevos por semana en Las Condes, mientras que alcanza a más de 2.500 casos nuevos por semana en La Florida.

En un trabajo reciente realizado por unos de los autores de esta columna (Berardo, 2021), se intenta medir el efecto de las cuarentenas en Chile usando datos del período abril 2020 a septiembre 2020. La metodología utilizada tiene en cuenta que el crecimiento de los casos puede hacer que: (i) el gobierno decrete la cuarentena, (ii) las personas cambien su comportamiento (reduzcan su movilidad, respeten el distanciamiento social, etc.), y (iii) aumenten los casos en

\section{Figura 1: Casos nuevos, movilidad y cuarentena, Abril 2020 - Septiembre 2020}

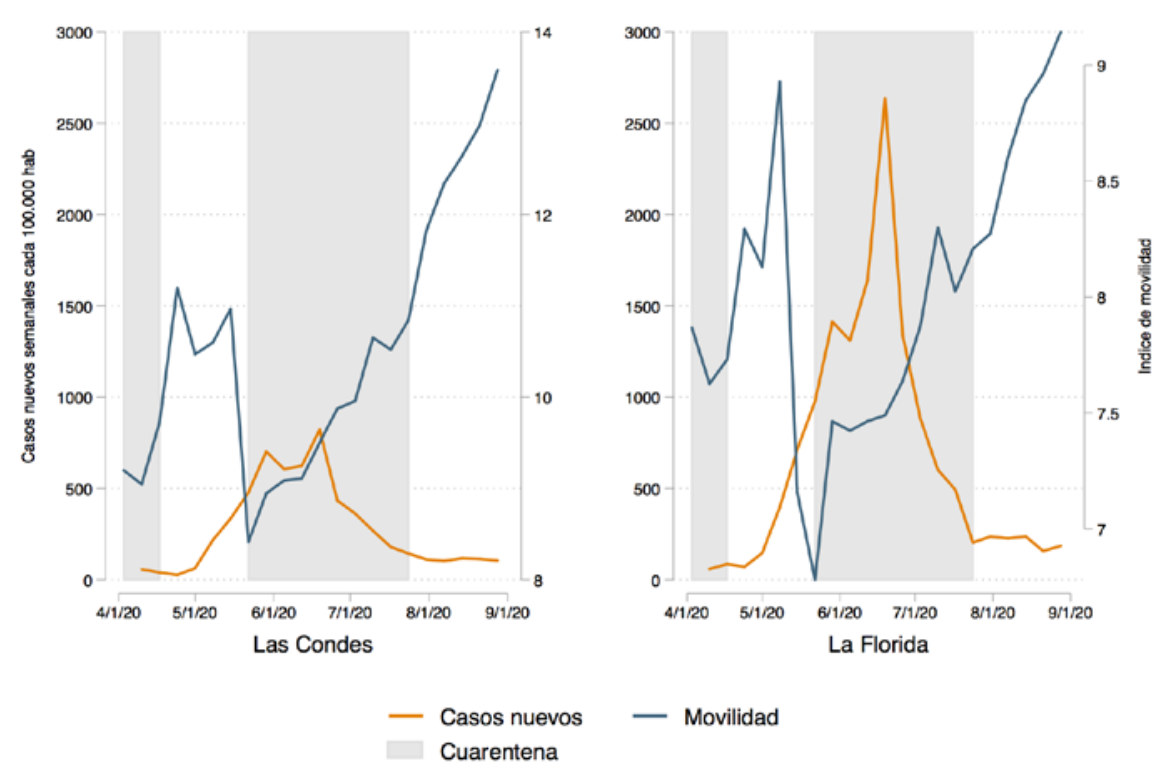

Fuente: Plan de Acción por Coronavirus del Gobierno de Chile, Índice de Movilidad de la Universidad del Desarrollo, e informes epidemiológicos publicados por el Ministerio de Salud de Chile.

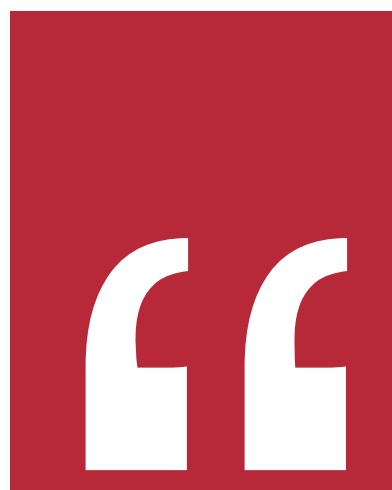

La cuarentena sí ha tenido efecto para reducir los contagios. Por ejemplo, el valor máximo de casos nuevos hubiese llegado a 5.000 por semana en Las Condes. Segundo, el efecto de las cuarentenas es muy distinto para Las Condes y La Florida. Según los resultados encontrados, las cuarentenas permitieron reducir los contagiados en un 85\% para Las Condes, pero un 68\% para La Florida 
Figura 2: Casos nuevos diarios con y sin cuarentena, Abril 2020 - Septiembre 2020

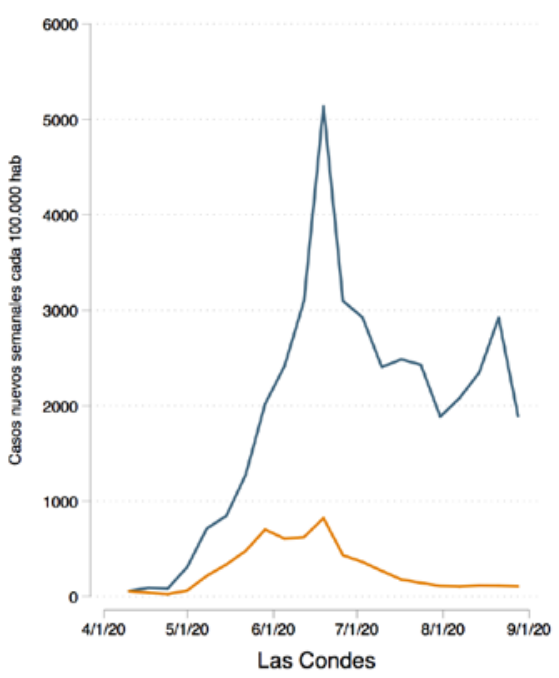

- Casos nuevos (sin cuarentena)

Fuente: Informes epidemiológicos publicados por el Ministerio de Salud de Chile (casos nuevos con cuarentena) y elaboración propia (casos nuevos sin cuarentena).

el futuro. Además, se permite que el anuncio de las cuarentenas pueda tener un efecto directo sobre los contagios (las personas usan más las mascarillas y se cuidan más) y un

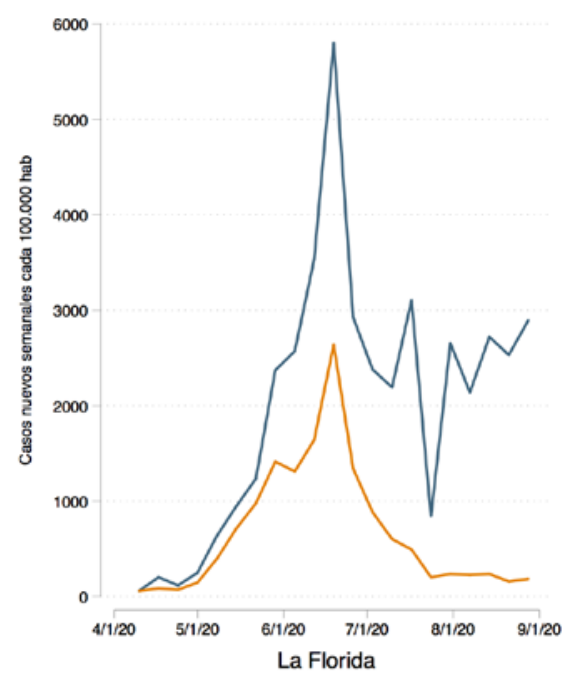

- Casos nuevos (con cuarentena)

na) yelaboracion propia (casos nuevos sin cuarentena).

efecto indirecto a través de la reducción de la movilidad.

Una vez estimado este modelo, se puede hacer la siguiente pregunta: ¿Qué hubiese

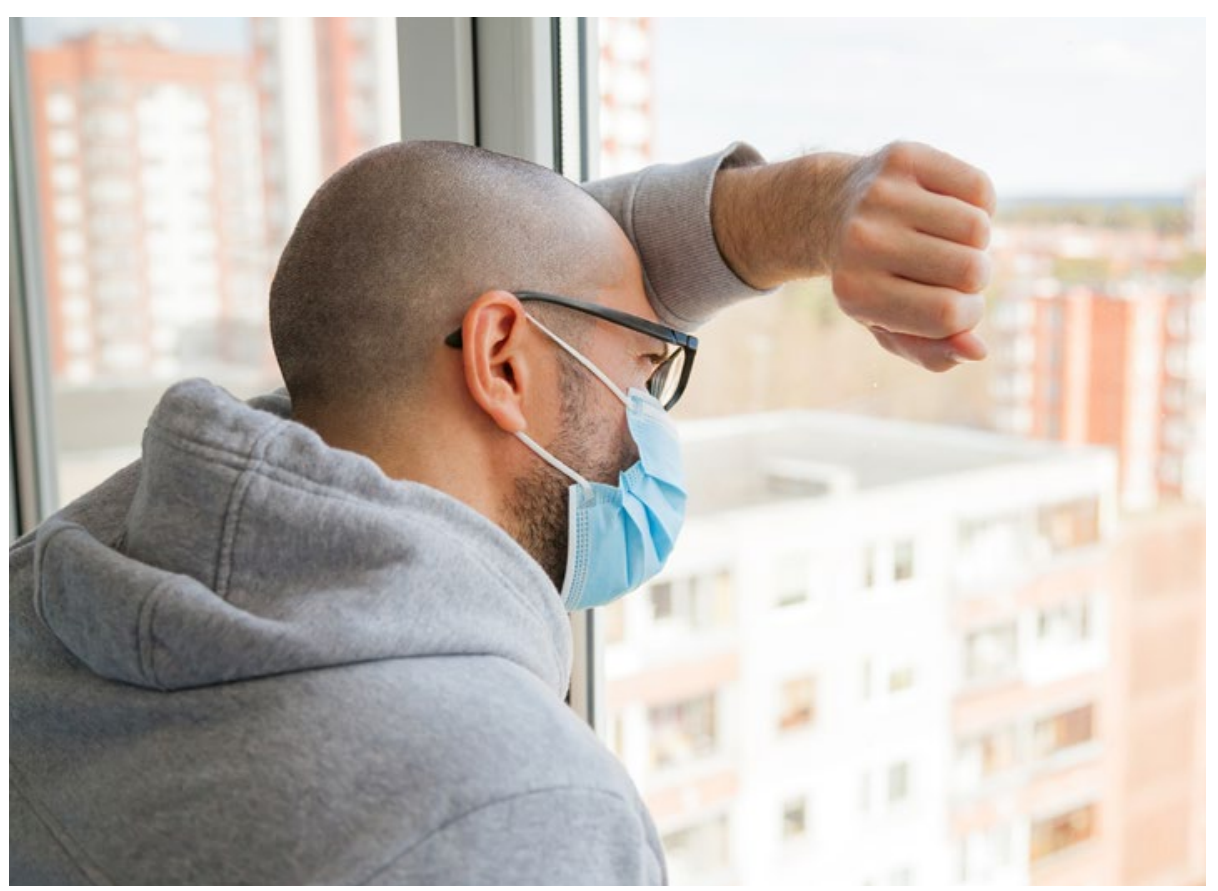

pasado con los contagios en caso de que no se implemente la cuarentena?

El modelo nos permite simular este escenario contrafactual que no se ha observado en la realidad. La Figura 2 muestra los casos nuevos observados en los datos con las cuarentenas implementadas (línea naranja) y los casos nuevos en el escenario sin cuarentenas (simulado por el modelo) para Las Condes y La Florida.

Hay dos resultados importantes. Primero, la cuarentena sí ha tenido efecto para reducir los contagios. Por ejemplo, el valor máximo de casos nuevos hubiese llegado a 5.000 por semana en Las Condes. Segundo, el efecto de las cuarentenas es muy distinto para Las Condes y La Florida. Según los resultados encontrados, las cuarentenas permitieron reducir los contagiados en un $85 \%$ para Las Condes, pero un 68\% para La Florida.

Es importante tener en cuenta las limitaciones de la evidencia disponible antes de incorporar los resultados en el diseño de políticas públicas. La pandemia del COVID-19 es un fenómeno reciente y puede que los efectos que se obtuvieron con datos del 2020 no sean extrapolables al 2021 porque: (i) la personas pueden estar agotadas de las políticas de cuarentena luego de más de un año de implementación, (ii) las efectividades de las cuarentenas ante nuevas cepas del virus pueden ser distintas, y (iii) el escenario contrafactual relevante ahora debería ser sin cuarentenas, pero con vacunación. Además, existen costos sociales y económicos de las cuarentenas que son muy relevantes para ver si es la política más idónea en el contexto actual.

A pesar de estas limitaciones, entender en base a evidencia creíble los efectos de las políticas implementadas para combatir el COVID-19 puede ayudar a mejorar estas políticas para el futuro y mejorar su implementación. $\mathbf{E}$

\section{Referencias}

- Berardo, Lucas Martín. ¿Funcionan los confinamientos? La respuesta de Chile a la pandemia. Tesis de Magister. Universidad Alberto Hurtado, Chile. 